\title{
Incidence of epidural haematoma and neurological injury in cardiovascular patients with epidural analgesia/anaesthesia: systematic review and meta-analysis Wilhelm Ruppen ${ }^{1,2}$, Sheena Derry ${ }^{1}$, Henry J McQuay ${ }^{1}$ and R Andrew Moore*1
}

Address: ${ }^{1}$ Pain Research and Nuffield Department of Anaesthetics, University of Oxford, Oxford Radcliffe NHS Trust, The Churchill Headington, Oxford, OX3 7LJ, UK and 2University Hospital Basel, Department Anaesthesia, CH-4031 Basel, Switzerland

Email: Wilhelm Ruppen - wruppen@freesurf.ch; Sheena Derry - sheena.derry@pru.ox.ac.uk; Henry J McQuay - henry.mcquay@pru.ox.ac.uk; R Andrew Moore* - andrew.moore@pru.ox.ac.uk

* Corresponding author

Published: 12 September 2006

BMC Anesthesiology 2006, 6:10 doi:10.1 186/147/-2253-6-10

This article is available from: http://www.biomedcentral.com/I47/-2253/6/10

(C) 2006 Ruppen et al; licensee BioMed Central Ltd.

This is an Open Access article distributed under the terms of the Creative Commons Attribution License (http://creativecommons.org/licenses/by/2.0), which permits unrestricted use, distribution, and reproduction in any medium, provided the original work is properly cited.

\begin{abstract}
Background: Epidural anaesthesia is used extensively for cardiothoracic and vascular surgery in some centres, but not in others, with argument over the safety of the technique in patients who are usually extensively anticoagulated before, during, and after surgery. The principle concern is bleeding in the epidural space, leading to transient or persistent neurological problems.
\end{abstract}

Methods: We performed an extensive systematic review to find published cohorts of use of epidural catheters during vascular, cardiac, and thoracic surgery, using electronic searching, hand searching, and reference lists of retrieved articles.

Results: Twelve studies included I4, I05 patients, of whom 5,026 (36\%) had vascular surgery, 4,97। $(35 \%)$ cardiac surgery, and 4,108 $(29 \%)$ thoracic surgery. There were no cases of epidural haematoma, giving maximum risks following epidural anaesthesia in cardiac, thoracic, and vascular surgery of $I$ in I,700, I in I,400 and I in I,700 respectively. In all these surgery types combined the maximum expected rate would be I in 4,700. In all these patients combined there were eight cases of transient neurological injury, a rate of I in I,700 (95\% confidence interval I in 3,300 to I in 850). There were no cases of persistent neurological injury (maximum expected rate $I$ in 4,600).

Conclusion: These estimates for cardiothoracic epidural anaesthesia should be the worst case. Limitations are inadequate denominators for different types of surgery in anticoagulated cardiothoracic or vascular patients more at risk of bleeding.

\section{Background}

Epidural anaesthesia and analgesia are widely and successfully used to alleviate perioperative pain. The technique claims to offer many advantages, such as improved cardio-pulmonary function, less intraoperative anaes- thetic, improved postoperative gut function, early tracheal extubation, and better mobilisation. There is concern, however, about its use in patients with perioperative anticoagulation, because of the risk of bleeding, which could 
cause serious adverse events like epidural haematoma and neurological injury.

While potential benefits of epidural anaesthesia and analgesia may be immediate and well reported, information about rare adverse events is more difficult to come by. Because serious harm is uncommon, even large cohorts may report no events. When catheters are used for a short time, as in obstetrics, risks have been calculated [1]: epidural haematoma 1 in 168,000 women, deep epidural infection 1 in 145,000, persistent neurological injury (lasting more than one year) 1 in 240,000, and transient neurological injury (lasting less than one year) 1 in 6700 . On the other hand, one person in 35 having a long-term epidural catheter for an average of 70 days for relief of cancer pain can be expected to have a deep epidural infection (unpublished results from a systematic review).

Using epidural catheters in cardiovascular anaesthesia is likely to present risks somewhere between these extremes. The aim of this study was to determine the rates of epidural bleeding and neurological injury for chronic epidural indwelling catheters from available cohorts in cardiovascular and thoracic surgery. This updates a previous review by Ho and colleagues [2] based on 4,600 reported cases of epidural anaesthesia up to 1999 in which no events had occurred. The outcome in this study [2] was the number of cases of epidural anaesthesia in cardiovascular surgery; it so happened that no serious adverse events were reported. We chose purposefully to look for cohorts that positively reported whether events had occurred or not. The difference is no report of an event (a passive approach), and the report of no events (an active approach).

\section{Methods}

We searched for studies reporting adverse events of cardiovascular anaesthesia in PubMed (from 1966), EMBASE (from 1980), and MEDLINE (from 1966) to February 2005, with no restrictions for language or type of study [1]. Five journals (Anesthesiology, Anesthesia and Analgesia, British Journal of Anaesthesia, Anaesthesia, Acta Anaesthesiologica Scandinavica) were hand-searched from mid-1999 to 2005. Reference lists were checked for additional studies (Figure 1).

Full paper copies were obtained for all studies not eliminated after reading title and abstract. We then selected those reporting on at least 100 cardiovascular or thoracic surgery patients, and with numerical data for serious adverse effects such as haematoma and neurological injuries. This was an arbitrary limit, and previous work has shown that most information on patients comes from larger studies, with small studies contributing a small proportion of patients overall [1]. We took definitions of

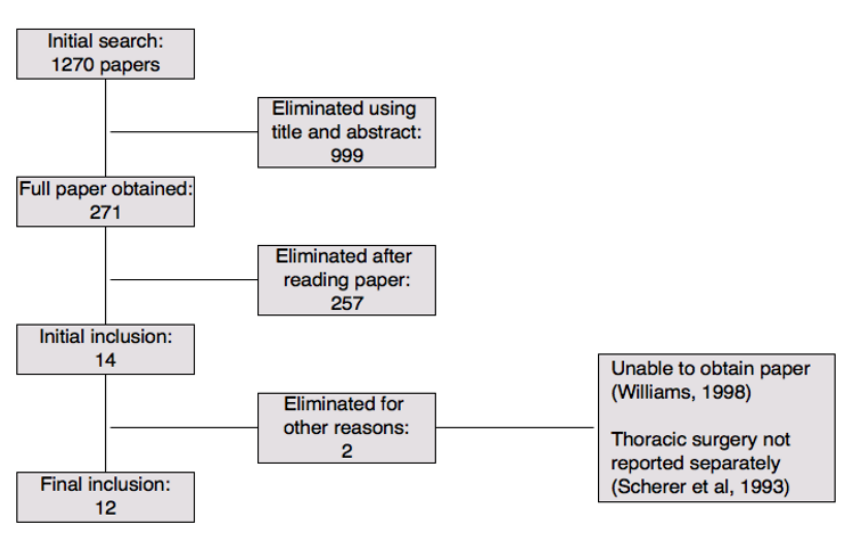

\section{Figure I}

Flow diagram of selection of studies for inclusion for data analysis.

adverse events as described by the authors of the individual studies. For neurological injuries, we were interested in those that were transient (resolved within one year), and persistent (not resolved within one year).

Information about the type of study, patients, intervention, and numbers experiencing individual adverse outcomes was tabulated. We did not use quality-scoring systems. QUOROM guidelines were followed where applicable. It was the intention, provided there was sufficient clinical homogeneity, to pool results and calculate an overall complication rate using the exact binomial method to determine the $95 \%$ confidence interval [3]. For these calculations, a study was included only if it mentioned an adverse event was present or definitely not present; studies not mentioning the adverse event were omitted from that particular calculation. We intended to perform sensitivity analyses if there was sufficient information, for instance for larger versus smaller studies, or more recent versus older studies.

\section{Results}

We identified a large number of papers (1270), with an eventual reference list of 271 papers relating to epidural harm (Figure 1). Fourteen [4-17] related to cardio-vascular-thoracic surgery patients. We could not obtain a copy of one paper [17]. We excluded another [12] reporting on a large series of thoracic and thoracic-abdominal patients because it did not describe results separately. Twelve studies [4-11,13-16] met our search criteria [see Additional file $1]$. Five studies $[4,5,13-15]$ ( $42 \%$ of studies but only $14 \%$ of patients) were identified by electronic searches, one [6] ( $8 \%$ of studies; $31 \%$ of patients) by hand searching, and six $[7-11,16]$ ( $50 \%$ of studies; $55 \%$ of patients) by examination of reference lists and reviews. 
Three $[4,7,10]$ of the 12 studies concerned vascular surgery and epidural use, and eight [5,8-10,13-16] cardiac surgery, and one [6] included mostly thoracic surgery patients $(4,108$ thoracic and 245 cardiac). There were 14,105 patients in total, of whom 5,026 patients (36\%) had vascular surgery, 4,971 patients $(35 \%)$ cardiac surgery, and 4,108 patients (29\%) thoracic surgery.

All cardiac patients were fully heparinised, and 4,054 of the 4,108 patients (99\%) undergoing thoracotomy [6] typically received heparin $5000 \mathrm{U}$ subcutaneously two hours before surgery and then every 12 hours while immobilized. All three studies reporting on vascular surgery $[4,7,10]$ reported extensive anticoagulation of patients.

\section{Epidural haematoma}

There were no cases of epidural haematoma in 4,971 cases of cardiac surgery, 4,108 cases of thoracic surgery, and 5,026 cases of vascular surgery (Table 1 ).

\section{Neurological injury}

Ten studies [4,6-12,16] $(13,422$ patients) reported on transient neurological injury, with eight cases described in two of them $[10,16]$ (Table 1). This was a risk of 8 in 13,422 patients $(0.06 \%, 95 \%$ confidence interval $0.03 \%$ to $0.12 \%$; a rate of 1 in $1,700,95 \%$ confidence interval 1 in 3,300 to 1 in 850 ).

None of the eleven studies $[4-11,13,14,16] \quad(13,827$ patients) reporting on permanent neurological injury found any persistent neurological injury.

\section{Discussion}

Results concerning postoperative morbidity with perioperative epidural analgesia have been contradictory. Some studies $[18,19]$ found an improved outcome for patients with thoracic epidural analgesia, whereas others [20-22] did not find any difference between thoracic epidural analgesia and systemic analgesia [12]. Kehlet \& Wilmore [23] included neuraxial blockade as one of the key elements for accelerated recovery from surgery, though mainly in the context of visceral rather than cardiac or thoracic surgery.

In cardiovascular surgery there is some evidence that epidural anaesthesia and analgesia improves haemodynamic stability [24-27], coronary perfusion [28-30], ventricular function [31-33], pulmonary function [33-35], intense analgesia [27,33-38], early tracheal extubation [28,33$35,40,41]$, and metabolic profile [24,26], and decreases ischemia [28] and the incidence of arrhythmias [14]. On the other hand, Hemmerling [39] found no difference in fast track extubation or in haemodynamic stability between the use of epidural analgesia or systemic opioid analgesia, and Samama [42] suggested in a review that epidurals should not be used in vascular surgery patients.

A meta-analysis [43] of the effects of perioperative central neuraxial analgesia on outcomes after coronary artery bypass surgery (15 studies, 1178 patients) reported no reduction in mortality or myocardial infarction after thoracic epidural analgesia compared with general anaesthesia, though a small reduction might be difficult to see with this limited number of patients. However, there were significant reductions in the risk of dysrrhythmias, pulmonary complications, time to tracheal extubation, and pain scores at rest and with activity. A recent review [44] of intrathecal and epidural anaesthesia and analgesia for cardiac surgery, suggests that while they provide enhanced postoperative analgesia, a "clinically important effect on morbidity and mortality" has not yet been demonstrated.

Table I: Events found in different patient groups

\begin{tabular}{lcccccc}
\hline Author & Surgery & Year & Patients & $\begin{array}{c}\text { Transient neurological } \\
\text { events }\end{array}$ & $\begin{array}{c}\text { Persistent neurological } \\
\text { events }\end{array}$ & Epidural haematoma \\
\hline Baron [4] & Vascular & 1987 & 912 & 0 & 0 & 0 \\
Odoom [7] & Vascular & 1983 & 950 & 0 & 0 & 0 \\
Rao [10] & Vascular & 1981 & 3164 & 4 & 0 & 0 \\
Horlocker [6] & Thoracic & 2003 & 4108 & 0 & 0 & 0 \\
Chakravarthy [16] & Cardiac & 2005 & 2113 & 4 & 0 & 0 \\
Horlocker [6] & Cardiac & 2003 & 245 & 0 & 0 & 0 \\
Pastor [9] & Cardiac & 2003 & 714 & 0 & 0 & 0 \\
Canto [5] & Cardiac & 2002 & 305 & no data & 0 & 0 \\
Oxelbark [8] & Cardiac & 2001 & 250 & 0 & 0 & 0 \\
Scott [13] & Cardiac & 2001 & 408 & no data & no data & 0 \\
Warters [15] & Cardiac & 2000 & 278 & 0 & 0 & 0 \\
Sanchez [II] & Cardiac & 1998 & 558 & no data & 0 & 0 \\
Turfrey [14] & Cardiac & 1997 & 100 & $\mathbf{8}$ & $\mathbf{0}$ & 0 \\
\hline Total & & & $\mathbf{1 4 1 0 5}$ & & & 0
\end{tabular}


Any benefits from epidural analgesia have to be balanced by the potential for harm, which might be serious. In 2004 Rosen et al [45] described a favourable outcome in the first case of an epidural haematoma in an adolescent patient after cardiac surgery. Martinez-Palli et al [46] also reported an epidural haematoma in a patient receiving epidural analgesia for vascular surgery. As case reports, these studies had no denominator, so no estimate of adverse event rate could be calculated.

More than 800,000 patients have coronary artery bypass surgery a year [43], and even low adverse event rates could give rise to a significant number of patients harmed. The best estimates we could find for cardiovascular patients with epidural analgesia/anaesthesia, were no cases of epidural haematoma in 14,105 patients, eight cases of transient neurological injury in 13,422 patients, and no cases of persistent neurological injury in 13,827 patients.

According to the mathematical model of the "rule of 3" by Hanley and Lippman-Hand [47], when there are no events the 95\% confidence interval that the event will not occur 1 in the total divided by three $(\mathrm{n} / 3)$. Where no events have occurred, as here with epidural haematoma, the estimate of maximum rate is entirely dependant on the size of the denominator; with no events in 1000 patients the maximum risk is 1 in 333, becoming 1 in 3,333 in 10,000 patients.

Using the rule of 3 the maximum risk for these epidural haematoma therefore becomes 14,105 divided by 3 , or $0.02 \%$, or 1 in 4,700 patients. For transient neurological injury we found eight cases in 13,422 , or $0.06 \%$, or 1 in 1,700 patients. Again using the Hanley and LippmanHand formula for persistent neurological injury where there were no events in 13,827 patients, we might expect a maximum rate of $0.02 \%$ or 1 in 4,600 patients.

Because of the apparent simplicity of the rule of 3, we also used the exact binomial calculation [3] to estimate an upper confidence interval for the proportion when there were no events. The inverse of this proportion becomes a frequency. The comparison between the two methods is shown in Table 2. The exact method produced a slightly higher risk estimate, but not with any clinical significance given that there had been no events. The rule of 3 has the advantage of being amenable to mental arithmetic, or at worst a simple calculator.

We have assumed that the underlying risk for epidural haematoma or persistent neurological injury is about the same in cardiac surgery, thoracic surgery, and vascular surgery. Others may disagree. In that event we use the smaller denominators for each group separately, generating maximum risks of 1 in 1,700, 1 in 1,400 and 1 in 1,700 for epidural anaesthesia in cardiac, thoracic, and vascular surgery respectively using the rule of 3 (Table 2). The fact that these risks look similar is an accident of having similar numbers of patients $(4,900,4,100$, and 5,000$)$ for the denominator.

Because the previous attempt to estimate the risk of haematoma with epidural anaesthesia in cardiac surgery used a denominator of 4,600 patients, the result for cardiac surgery is similar to our estimate. The difference in approach is important. Ho and colleagues [2] sought the number of cases of epidural anaesthesia in cardiac surgery, and assumed that the lack of any report of epidural haematoma was the same as no event. This depends on the complete reporting of events, yet there is abundant literature to show that serious adverse events are grossly underreported in situations as disparate as paediatric intensive care [48] and acupuncture [49]. Under-reporting may be influenced by a variety of factors, including litigation.

Our approach was to look only for larger studies with a positive report of either events or lack of them (showing that they had been looked for), and where there was both a nominator (the number of events) and a denominator (the number of cases). Case reports or case series without

Table 2: Comparison of rule of 3 and exact binomial estimates of risk

\begin{tabular}{|c|c|c|c|c|}
\hline \multirow[b]{2}{*}{ Outcome } & \multicolumn{2}{|c|}{ Number of } & \multicolumn{2}{|c|}{ Lower $95 \%$ of risk } \\
\hline & Events & Patients & rule of 3 & Exact $\mathbf{C l}$ \\
\hline \multicolumn{5}{|l|}{ Epidural haematoma } \\
\hline Cardiac & 0 & 4971 & 1 in 1,700 & 1 in 1,350 \\
\hline Thoracic & 0 & 4108 & 1 in 1,400 & 1 in 1,100 \\
\hline Vacular & 0 & 5026 & $I$ in 1,700 & 1 in 1,350 \\
\hline Combined & 0 & 14105 & 1 in 4,700 & 1 in 3,800 \\
\hline \multicolumn{5}{|l|}{ Permanent neurological injury } \\
\hline Combined & 0 & 13827 & 1 in 4,600 & I in 3,750 \\
\hline
\end{tabular}


a denominator tell us only that serious adverse events can happen; they cannot address the rate at which they happen.

A possible limitation is that we limited our search to studies of 100 patients. This was for practical reasons. We reasoned that few cohort studies with both nominator and denominator would be likely to have been done, and previous experience in obstetric anaesthesia [1] showed that $85 \%$ of cases were found in larger studies (in that case 10,000 women or more). We also know that observational studies are difficult to find electronically $[1,50]$, and personal experience is that requests for additional information are rarely helpful. Although we could probably have increased denominators by considerable additional searching or including any smaller studies that may exist, it is unlikely that any substantial difference would have resulted.

\section{Conclusion}

The estimates presented here for cardiothoracic epidural anaesthesia should be the worst case. It is limited by inadequate denominators for different types of surgery in anticoagulated cardiothoracic or vascular patients more at risk of bleeding. The maximum risks for epidural haematoma were estimated as 1 in 1,700, 1 in 1,400 and 1 in 1,700 for epidural anaesthesia in cardiac, thoracic, and vascular surgery respectively, or 1 in 4,700 if we are content that the risk in these three types of surgery are sufficiently similar to combine them.

\section{Competing interests}

The author(s) declare that they have no competing interests.

\section{Authors' contributions}

RAM, HJM, and WR were involved with the original concept and planning the study. WR and SD did data extraction and analysis. WR and RAM prepared the initial manuscript, and all authors read and approved the final manuscript.

\section{Additional material}

\section{Additional file 1}

Details of included papers. Details of the studies, including the number of patients, the indication for surgery, study design, details of methods and main results.

Click here for file

[http://www.biomedcentral.com/content/supplementary/14712253-6-10-S1.pdf]

\section{Acknowledgements}

Pain Research is supported in part by the Oxford Pain Research Trust. The organisation had no role in design, planning, or execution of the study. We are grateful for some stimulating and helpful comments of reviewers.

\section{References}

I. Ruppen W, Derry S, McQuay H, Moore RA: Incidence of epidural hematoma, infection and neurological injury in obstetric patients with epidural analgesia/anesthesia: meta-analysis. Anesthesiology 2006, 105:394-399.

2. Ho AM, Chung DC, Joynt GM: Neuraxial blockade and hematoma in cardiac surgery. Estimating the risk of a rare adverse event that has not (yet) occurred. Chest 2000, I | 7:55 |-555.

3. Vollset SE: Confidence intervals for a binomial proportion. Stat Med 1993, I 2:809-824.

4. Baron HC, LaRaja RD, Rossi G, Atkinson D: Continuous epidural analgesia in the heparinized vascular surgical patient: a retrospective review of 912 patients. J Vasc Surg 1987, 6: |44- |46.

5. Canto M, Casas A, Sanchez MJ, Lorenzo A, Bataller L: Thoracic epidurals in heart valve surgery: neurologic risk evaluation. J Cardiothorac Vasc Anesth 2002, I 6:723-726.

6. Horlocker TT, Abel MD, Messick JM, Schroeder DR: Small risk of serious neurologic complications related to lumbar epidural catheter placement in anesthetized patients. Anesth Analg 2003, 96:1547-1552.

7. Odoom JA, Sih IL: Epidural analgesia and anticoagulant therapy. Experience with one thousand cases of continuous epidurals. Anaesthesia 1983, 38:254-259.

8. Oxelbark S, Bengtsson L, Eggersen M, Kopp J, Pedersen J, Sanchez R: Fast track as a routine for open heart surgery. Eur J Cardiothorac Surg 2001, 19:460-463.

9. Pastor MC, Sanchez MJ, Casas MA, Mateu J, Bataller ML: Thoracic epidural analgesia in coronary artery bypass graft surgery: seven years' experience. J Cardiothorac Vasc Anesth 2003, I 7:154-159.

10. Rao TL, El-Etr AA: Anticoagulation following placement of epidural and subarachnoid catheters: an evaluation of neurologic sequelae. Anesthesiology 1981, 55:618-620.

II. Sanchez R, Nygard E: Epidural anesthesia in cardiac surgery: is there an increased risk? J Cardiothorac Vasc Anesth 1998 , I 2:170-173.

12. Scherer R, Schmutzler M, Giebler R, Erhard J, Stocker L, Kox WJ: Complications related to thoracic epidural analgesia: a prospective study in 107 I surgical patients. Acta Anaesthesiol Scand 1993, 37:370-374.

13. Scott NB, Turfrey DJ, Ray D, Nzewi O, Sutcliffe NP, Lal AB, Norrie J, Nagels WJ, Ramayya GP: A prospective randomized study of the potential benefits of thoracic epidural anesthesia and analgesia in patients undergoing coronary artery bypass grafting. Anesth Analg 2001, 93:528-535.

14. Turfrey DJ, Ray DA, Sutcliffe NP, Ramayya P, Kenny GN, Scott NB: Thoracic epidural anaesthesia for coronary artery bypass graft surgery. Effects on postoperative complications. Anaesthesia 1997, 52:1090-1095.

15. Warters D, Koch SM, Luehr S, Knight W: Thoracic epidurals in coronary artery bypass surgery. Anesth Analg 2000, 90:767.

16. Chakravarthy $M$, Thimmangowda P, Krishnamurthy I, Nadiminti S, Jawali V: Thoracic epidural anesthesia in cardiac surgical patients: a prospective audit of 2, I I 3 cases. J Cardiothorac Vasc Anesth 2005, 19:44-48.

17. Wiliams J: Thoracic epidural anesthesia for cardiac surgery. Tech Reg Anesth Pain Manage 1998, 2:41-55.

18. Hasenbos M, van Egmond J, Gielen M, Crul JF: Post-operative analgesia by high thoracic epidural versus intramuscular nicomorphine after thoracotomy. Part III. The effects of per- and post-operative analgesia on morbidity. Acta Anaesthesiol Scand |987, 3 |:608-615.

19. Benhamou D, Samii K, Noviant Y: Effect of analgesia on respiratory muscle function after upper abdominal surgery. Acta Anaesthesiol Scand 1983, 27:22-25.

20. Bredtmann RD, Kniesel B, Herden HN, Teichmann W: The effect of continuous thoracic peridural anesthesia on the pulmonary function of patients undergoing colon surgery. Results of a randomized study of 116 patients. Reg Anaesth I99I, I4:2-8. 
21. Hendolin H, Lahtinen J, Lansimies E, Tuppurainen T: The effect of thoracic epidural analgesia on postoperative stress and morbidity. Ann Chir Gynaecol 1987, 76:234-240.

22. Seeling W, Bruckmooser KP, Hufner C, Kneitinger E, Rigg C, Rockemann $M$ : No reduction in postoperative complications by the use of catheterized epidural analgesia following major abdominal surgery. Anaesthesist 1990, 39:33-40.

23. Kehlet $\mathrm{H}$, Wilmore $\mathrm{DW}$ : Multimodal strategies to improve surgical outcome. Am / Surg 2002, I 83:630-64I.

24. Moore CM, Cross MH, Desborough JP, Burrin JM, Macdonald IA, Hall GM: Hormonal effects of thoracic extradural analgesia for cardiac surgery. $\mathrm{Br}$ J Anaesth 1995, 75:387-393.

25. Stenseth R, Bjella L, Berg EM, Christensen O, Levang OW, Gisvold SE: Thoracic epidural analgesia in aortocoronary bypass surgery. I: Haemodynamic effects. Acta Anaesthesiol Scand 1994 38:826-833.

26. Kirno K, Friberg P, Grzegorczyk A, Milocco I, Ricksten SE, Lundin S: Thoracic epidural anesthesia during coronary artery bypass surgery: effects on cardiac sympathetic activity, myocardial blood flow and metabolism, and central hemodynamics. Anesth Analg 1994, 79:1075-108I.

27. Hoar PF, Hickey RF, Ullyot DJ: Systemic hypertension following myocardial revascularization. A method of treatment using epidural anesthesia. J Thorac Cardiovasc Surg 1976, 7 I:859-864.

28. Loick HM, Schmidt C, Van Aken H, Junker R, Erren M, Berendes E, Rolf N, Meissner A, Schmid C, Scheld HH, Mollhoff T: High thoracic epidural anesthesia, but not clonidine, attenuates the perioperative stress response via sympatholysis and reduces the release of troponin $\mathrm{T}$ in patients undergoing coronary artery bypass grafting. Anesth Analg 1999, 88:70 I-709.

29. Blomberg S, Emanuelsson H, Kvist H, Lamm C, Ponten J, Waagstein F, Ricksten SE: Effects of thoracic epidural anesthesia on coronary arteries and arterioles in patients with coronary artery disease. Anesthesiology 1990, 73:840-847.

30. Blomberg S, Emanuelsson H, Ricksten SE: Thoracic epidural anesthesia and central hemodynamics in patients with unstable angina pectoris. Anesth Analg 1989, 69:558-562.

31. Kock M, Blomberg S, Emanuelsson H, Lomsky M, Stromblad SO, Ricksten SE: Thoracic epidural anesthesia improves global and regional left ventricular function during stress-induced myocardial ischemia in patients with coronary artery disease. Anesth Analg 1990, 71:625-630.

32. Schmidt C, Hinder F, Van Aken H, Theilmeier G, Bruch C, Wirtz SP, Burkle H, Guhs T, Rothenburger M, Berendes E: The effect of high thoracic epidural anesthesia on systolic and diastolic left ventricular function in patients with coronary artery disease. Anesth Analg 2005, 100:156I-1569.

33. Shayevitz JR, Merkel S, O'Kelly SW, Reynolds PI, Gutstein HB: Lumbar epidural morphine infusions for children undergoing cardiac surgery. J Cardiothorac Vasc Anesth 1996, 10:217-224.

34. el-Baz N, Goldin M: Continuous epidural infusion of morphine for pain relief after cardiac operations. J Thorac Cardiovasc Surg 1987, 93:878-883.

35. Liem TH, Hasenbos MA, Booij LH, Gielen MJ: Coronary artery bypass grafting using two different anesthetic techniques: Part 2: Postoperative outcome. J Cardiothorac Vasc Anesth 1992 6:|156-|6|

36. Joachimsson PO, Nystrom SO, Tyden H: Early extubation after coronary artery surgery in efficiently rewarmed patients: a postoperative comparison of opioid anesthesia versus inhalational anesthesia and thoracic epidural analgesia. J Cardiothorac Anesth 1989, 3:444-454.

37. Robinson RJ, Brister S, Jones E, Quigly M: Epidural meperidine analgesia after cardiac surgery. Can Anaesth Soc J 1986, 33:550-555.

38. Desborough JP: Thoracic epidural analgesia in cardiac surgery. Anaesthesia 1996, 51:805-807.

39. Hemmerling TM, Le N, Olivier J, Choiniere JL, Basile F, Prieto I: Immediate extubation after aortic valve surgery using high thoracic epidural analgesia or opioid-based analgesia. / Cardiothorac Vasc Anesth 2005, 19: I76-I8I.

40. Priestley MC, Cope L, Halliwell R, Gibson P, Chard RB, Skinner M Klineberg PL: Thoracic epidural anesthesia for cardiac surgery: the effects on tracheal intubation time and length of hospital stay. Anesth Analg 2002, 94:275-282.
4I. Swenson JD, Hullander RM, Wingler K, Leivers D: Early extubation after cardiac surgery using combined intrathecal sufentanil and morphine. J Cardiothorac Vasc Anesth 1994, 8:509-5I4.

42. Samama CM, Baillard C: Locoregional neuraxial anesthesia as used in vascular surgery. Can J Anaesth 200I, 48:72-77.

43. Liu SS, Block BM, Wu CL: Effects of perioperative central neuraxial analgesia on outcome after coronary artery bypass surgery: a meta-analysis. Anesthesiol 2004, I 0 I: I53-16I.

44. Chaney MA: Intrathecal and epidural anesthesia and analgesia for cardiac surgery. Anesth Analg 2006, 102:45-64.

45. Rosen DA, Hawkinberry DW, Rosen KR, Gustafson RA, Hogg JP, Broadman LM: An epidural hematoma in an adolescent patient after cardiac surgery. Anesth Analg 2004, 98:966-969.

46. Martinez-Palli G, Sala-Blanch X, Salvado E, Acosta M, Nalda MA: Epidural hematoma after epidural anesthesia in a patient with peripheral vascular disease. Case report. Reg Anesth 1996, 21:342-346

47. Hanley JA, Lippman-Hand A: If nothing goes wrong, is everything all right? Interpreting zero numerators. JAMA I983, 249: $1743-1745$.

48. Ricci M, Goldman AP, de Leval MR, Cohen GA, Devaney F, Carthey $\mathrm{J}$ : Pitfalls of adverse event reporting in paediatric cardiac intensive care. Arch Dis Child 2004, 89:856-859.

49. Endres HG, Molsberger A, Lungenhausen M, Trampisch HJ: An internal standard for verifying the accuracy of serious adverse event reporting: the example of an acupuncture study of 190,924 patients. Eur J Med Res 2004, 9:545-55 I.

50. Lemeshow AR, Blum RE, Berlin JA, Stoto MA, Colditz GA: Searching one or two databases was insufficient for meta-analysis of observational studies. J Clin Epidemiol 2005, 58:867-873.

\section{Pre-publication history}

The pre-publication history for this paper can be accessed here:

http://www.biomedcentral.com/1471-2253/6/10/prepub
Publish with BiolMed Central and every scientist can read your work free of charge

"BioMed Central will be the most significant development for disseminating the results of biomedical research in our lifetime. "

Sir Paul Nurse, Cancer Research UK

Your research papers will be:

- available free of charge to the entire biomedical community

- peer reviewed and published immediately upon acceptance

- cited in PubMed and archived on PubMed Central

- yours - you keep the copyright
BiolMedcentral 